\title{
Configurações
}

Revista de sociologia

\section{O stalking nos acórdãos da Relação de Portugal: a compreensão do fenómeno antes da tipificação}

Stalking in the Rulings of Courts in Portugal: Understanding the Phenomenon before Classification

Le Stalking dans les arrêts des Cours d'appel portugaises: La Compréhension du Phénomène avant sa typification

\section{Sephora Marchesini}

\section{OpenEdition}

\section{Journals}

Edição electrónica

URL: http://journals.openedition.org/configuracoes/2847

DOI: $10.4000 /$ configuracoes.2847

ISSN: 2182-7419

\section{Editora}

Centro de Investigação em Ciências Sociais

Edição impressa

Data de publição: 18 Dezembro 2015

Paginação: 55-74

ISBN: 1646-5075

ISSN: 1646-5075

\section{Refêrencia eletrónica}

Sephora Marchesini, « O stalking nos acórdãos da Relação de Portugal: a compreensão do fenómeno antes da tipificação », Configurações [Online], 16 | 2015, posto online no dia 29 dezembro 2015, consultado o 30 abril 2019. URL : http://journals.openedition.org/configuracoes/2847 ; DOI : 10.4000/ configuracoes. 2847 
Marchesini, Sephora - 0 stalking nos acórdãos da relação de Portugal:

a compreensão do fenómeno antes da tipificação. Configurações, vol. 16, 2015, pp. 55-74

\title{
O stalking nos acórdãos da Relação de Portugal: a compreensão do fenómeno antes da tipificação
}

\author{
SEPHORA MARCHESINI*
}

Universidade de Coimbra

\begin{abstract}
Resumo
Nos últimos trinta anos o stalking vem sendo conhecido pelo mundo, havendo um desconsenso quanto ao potencial criminoso das condutas compreendidas por esse fenómeno. Portugal passou a se preocupar com essa conduta há menos de uma década, quando se iniciaram os estudos de prevalência processo que muito recentemente culminou na criminalização em 5 de agosto de 2015. A discussão, que se iniciou na área da Psicologia, resultou na criação do tipo penal de "Perseguição"; contudo, ao longo desse caminho, o debate pouco se desenvolveu na seara jurídica. Diante desse quadro, este breve estudo busca desocultar a percepção do fenómeno a partir dos Tribunais da Relação de Portugal em data anterior a sua tipificação, demonstrando que, para além dos estudos desenvolvidos no campo da Psicologia (vitimação e percepção), o tema já vinha sendo reconhecido e tratado pelos desembargadores portugueses.
\end{abstract}

Palavras-chave: stalking; assédio persistente; perseguição; violência doméstica.

\begin{abstract}
Stalking in the Rulings of Courts in Portugal:

Understanding the Phenomenon before Classification

In the last thirty years, stalking has been news throughout the world, without an agreement about the criminal potential of the behaviours included in this phenomenon. Portugal began to worry about this behaviour only in the last decade, when the prevalence studies started, which recently culminated in the criminalisation on the 5th August, 2015. The discussion, which started in the psychology field, resulted in the
\end{abstract}

\footnotetext{
* Bacharel em Direito pelo Centro de Ensino Superior dos Campos Gerais e Bacharel em História pela Universidade Estadual de Ponta Grossa. Mestre em Crime, Diferença e Desigualdade pela Universidade do Minho. Doutoranda da Faculdade de Direito da Universidade de Coimbra. Advogada inscrita na Ordem dos Advogados do Brasil e na Ordem dos Advogados de Portugal.
} 
creation of the criminal type "Perseguição" (Pursuit). However, along this path, little development was observed in the legal aspect. Given this situation, this brief study aims to unveil the perception of the phenomenon by the Courts of Appeal in Portugal before their classification, showing that in addition to the studies developed in the psychology field (victimisation and perception), the issue was already being recognised and handled by Portuguese Judges.

Keywords: stalking; persistent harassment; persecution; domestic violence.

\section{Résumé}

Le Stalking dans les arrêts des Cours d'appel portugaises :

\section{La Compréhension du Phénomène avant sa typification}

$\mathrm{Au}$ cours des trente dernières années, le harcèlement criminel (stalking) a été connu dans le monde entier, malgré l'existence d'un désaccord concernant le potentiel criminel des comportements liés à ce phénomène. Le Portugal a commencé à se soucier de tels comportements il y a moins d'une décennie, à l'occasion du début des études de prévalence, qui ont récemment, le 5 août 2015, abouti à la criminalisation. La discussion qui a commencé dans le domaine de la psychologie a mené à la création de la typification pénale de la "persécution ", néanmoins, au fil du temps, ce domaine légal śest peu développé. Compte tenu de cette situation, cette brève étude vise à dévoiler la perception du phénomène à partir des cours d'appel du Portugal (Tribunais da Relação de Portugal) à une date antérieure à leur typification, ce qui démontre que, outre les études menées dans le domaine de la psychologie (la victimisation et la perception), la question était déjà reconnue et traitée par les juges portugais.

Mots-clés: stalking ; harcèlement persistant ; persécutions ; violence domestique.

\section{Introdução}

Nos últimos trinta anos o stalking vem chamando a atenção da comunidade científica, que procura compreender o fenómeno de modo a apresentar a prevalência, os motivos de perpetração e os riscos, e a verificar padrões que levem a identificação de possíveis stalkers e vítimas. Mas inúmeras são as dificuldades encontradas no estudo desse fenómeno, como por exemplo, as diversas conceptualizações para o stalking e as diferentes metodologias de pesquisa empregadas nos estudos de prevalência, que impedem a delimitação do fenómeno, prejudicando a sua identificação e o consequente tratamento a ser aplicado às ocorrências. Por ser um fenómeno comum na população, muitas vezes passa despercebido, mesmo quando há sérias consequências para a saúde física e psicológica das vítimas e de seus familiares, chegando a interferir diretamente em outros aspectos da vida da vítima, como nas questões laborais e financeiras.

Antes de haver a criminalização do stalking pelos estados norte-americanos nos anos noventa, o comportamento era evidenciado apenas quando 
perpetrado contra estranhos e pessoas famosas. Os clínicos encaravam-no como "uma convicção delirante do perpetrador de que outra pessoa desconhecida ou famosa estava apaixonada por ele" (Lima, 2010), enquadrando-o num subtipo de Perturbação Delirante, como a erotomania. E com isso, é possível dizer, de certo modo, que foram as perseguições às celebridades as quais tiveram seus casos mediatizados que contribuíram para a tipificação nas legislações da perpetração de comportamentos persecutórios não desejados (Perez, 1993, cit. in Carvalho, 2010). Alguns desses casos foram as perseguições ao presidente Ronald Reagan, bem como a Jodie Foster, David Letterman, Nicole Simpson e, particularmente, o caso da atriz norte-americana Rebecca Schaeffer, que nos anos noventa levou a tipificação do stalking no estado da Califórnia. Entretanto hoje reconhecemos que qualquer um pode tornar-se um stalker, pois este é um fenómeno muito próximo de nós e infelizmente com altos índices de incidência.

Note-se que muitos países já publicaram uma legislação específica neste domínio; contudo, ainda não existem pesquisas que comprovem a sua eficácia. Noutros países, como é o caso do Brasil, existem apenas projetos de lei para a sua tipificação. Outros países, porém, ainda nem iniciaram estudos sobre a (des)necessidade da tipificação penal. Portugal é um dos países que foram impulsionados pelas investigações científicas para a criação de uma legislação anti-stalking, que se verificou apenas mais de duas décadas depois da primeira legislação criada no mundo (Estados Unidos).

Foi a partir das pesquisas nacionais desenvolvidas no campo da prevalência, em conjunto com o reconhecimento de diplomas internacionais como a Convenção do Conselho da Europa para a Prevenção e Combate da Violência Contra as Mulheres e da Violência Doméstica (de 11 de maio de 2011, na cidade de Istambul) e a Resolução 1962 inserida no Relatório da Comissão para a Igualdade e Não Discriminação (Doc. 13336 do dia 22 de novembro de 2013) da Assembleia Parlamentar do Conselho da Europa, que Portugal optou pela criação de um tipo penal específico para os casos de stalking.

Para além dos dois documentos internacionais citados, houve um parecer da Associação Portuguesa de Apoio à Vítima (APAV) que refere a necessidade da criminalização do stalking, assim como três projetos de lei para sua tipificação: o primeiro projeto de lei foi apresentado em 11 de setembro de 2014 pelo Partido Social Democrata e pelo CDS-Partido Popular (Projeto de lei n. ${ }^{\circ}$ 647/XII), e os outros dois no dia 19 do mesmo mês, propostos pelo Partido Socialista (Projeto de lei n. ${ }^{\circ}$ 659/XII/4. ${ }^{a}$ ) e pelo Bloco de Esquerda (Projeto de lei n. ${ }^{\circ}$ 663/XII/4. ${ }^{\circ}$ ). As propostas do PS e do PSD e CDS-PP são bastante semelhantes em sua redação, inserindo o tipo penal no artigo $154 .^{\circ}-\mathrm{A}$. Em contrapartida, a proposta do BE traz uma redação bastante semelhante à da tipificação italiana, inserindo o stalking no tipo penal 153 . $^{\circ}$-A.

A trigésima oitava alteração do Código Penal, de 5 de agosto de 2015, tipifica o crime de "Perseguição" (154. ${ }^{\circ}$-A), com uma redação do tipo penal 
bastante próxima da redação proposta no projeto-lei do PSD e do CDS-PP assim como no do PS. Tal demonstra que, apesar de ter avançado a curtos passos, Portugal reconheceu a existência do fenómeno, e consequentemente caminhou para a sua tipificação.

Diante desse quadro, o presente estudo vem apresentar o entendimento dos desembargadores nos últimos anos, quando ainda não havia tipificação, demonstrando que, apesar da não criminalização, o fenómeno já vinha sendo reconhecido e tratado pelos tribunais. Podemos ainda verificar que estes casos refletem os resultados das pesquisas de prevalência, em que se vislumbra a existência do stalking dentro da seara das relações afetivas, estando próximo do crime de violência doméstica.

\section{0 fenómeno stalking}

Segundo o Instituto Nacional de Justiça dos Estados Unidos (Tjaden \& Thoennes, 1998, cit. in Lima, 2010), o stalking configura "um comportamento repetido dirigido a uma pessoa, com o objetivo de efetuar contacto não desejado através da comunicação ou ameaças que causam alarme e medo no alvo".

Diversos são os aspectos que caracterizam a conduta de um stalker, sobretudo alguns comportamentos ${ }^{1}$ descritos na literatura (normalmente inofensivos quando vistos de forma isolada), a duração/frequência ${ }^{2}$, assim como as

1 A literatura internacional apresenta diversos comportamentos que podem ser enquadrados como stalking, classificando-os em grupos. Sheridan e colaboradores (2001, cit. in Coelho \& Gonçalves, 2007) dividem os comportamentos que compõem o stalking em três grupos: comportamentos de contacto, comportamentos violentos e comportamentos de procura de proximidade. Outras ações apontadas na literatura referem-se ao ataque a vítima, matar ou ameaçar, matar os seus animais de estimação (Draucker, 1999, cit. in Coelho \& Gonçalves, 2007), tentar estabelecer contacto por graffiti e e-mail, realizar encomendas em nome dos alvos ("a serem debitadas nas suas contas bancárias"), colocar falsos anúncios, encomendar coroas de flores, espalhar rumores a seu respeito, iniciar processos judiciais contra as vítimas de modo a antecipar as suas ações e manter o contacto com as mesmas no contexto jurídico (Tjaden \& Thoennes, 1998, cit. in Coelho \& Gonçalves, 2007). Pode ocorrer o uso da informática por parte do stalker, sendo então classificada como cyberstalking, internet stalking, computer stalking. No primeiro caso o stalking configura-se com o envio regular de e-mails "com conteúdos obscenos e/ou ameaçadores, de vírus e de mensagens de grandes dimensões"; o segundo caso ocorre quando se passa para o domínio público da internet - sala de conversação ou outras páginas, onde o stalker divulga fotos e dados pessoais da vítima; quando o perseguidor possui mais conhecimento informático, pode chegar ao terceiro tipo, o computer stalking, que ocorre quando o stalker assume o controlo do computador da vítima, acessando a todas as informações e ações realizadas com o equipamento (Ogilvi, 2000, cit. in Coelho \& Gonçalves, 2007).

2 A duração vem como um indicador da persistência da conduta; isso porque, segundo Purcell, Pathé \& Mullen (2004b, cit. in Matos et al., 2012), quando ultrapassado o período de duas semanas de assédio persistente/perseguição, é provável que a conduta se prolongue por vários meses ou até anos. E quanto maior for a duração, maior será o dano causado a vítima. Já Mullen e colaboradores (1999, cit. in Lima, 2010), em estudo posterior, defenderam que, para se verificar a presença de stalking, é preciso que ocorram pelo menos dez intrusões/comunicações durante o período mínimo de quatro semanas. Esta ideia contradizer estudos que identificam campanhas de assédio que perduram por duas semanas, assim como algumas legislações anti-stalking vigentes que estipulam que uma ocorrência ou duas são já suficientes para configuração do crime. 
consequências causadas na vítima ${ }^{3}$. A componente medo ${ }^{4}$ é muito discutida entre os autores quanto a sua necessidade para a configuração de crime, o que se reflete nas múltiplas redações legislativas dos países que criminalizaram o fenómeno. Cada país concebe o stalking de uma forma específica, muitas vezes divergente do descrito na literatura científica nacional.

3 O stalking acaba por provocar alterações emocionais na vítima, que, diante da constante intrusão indesejada, se sente impotente para combatê-la. Com isso, desenvolve alguns sintomas que podem assemelhar-se ao trauma crónico, levando à depressão, a ter ideação suicida, ansiedade e perturbação de estresse pós-traumático (PTSD) (Baldry, 2003, cit. in Coelho \& Gonçalves, 2007).

No estudo desenvolvido por Brewster (1998, cit. in Ferreira \& Matos, 2013), concluiu-se que quase a totalidade das vítimas, cerca de $99 \%$, experienciou uma redução da qualidade de vida, em consequência das condutas de seus ex-parceiros. No que tange às respostas emocionais, essas foram diferenciadas: em média $44,4 \%$ das vítimas reagem com desconfiança, $41,7 \%$ com medo, $31 \%$ com nervosismo e agitação, 26,7\% com raiva, 35,7\% com paranoia, e 21,4\% com sintomatologia depressiva.

Cupach e Spitzberg (2004, cit. in Lima, 2010) referiram 11 categorias de danos possíveis, em consequência da perpetração do stalking. São elas: 1 - danos gerais, que afectam a vida da vítima; 2 - com portamentais, que levam a vítima a alterar a sua rotina; 3 - afectivos, em que se verifica impacto na vida emocional; 4 - cognitivos, como a perda de confiança; 5 - físicos/fisiológicos, que podem levar a distúrbios do sono ou alimentares; 6 - sociais, com a diminuição das relações interpessoais; 7 - de recursos, em que a perseguição pode atrapalhar o exercício da profissão e consequentemente o rendimento profissional; 8 - espirituais, podendo a vítima perder a fé; 9 - na sociedade, com a percepção dos riscos de violência; 10 - ambivalentes, visto que há um embate entre a romantização e a autorresponsabilização pelo que vem ocorrendo; e 11 - mínimos, em que há uma ausência de efeitos negativos na vítima.

Nas palavras de Coelho e Gonçalves (2007), "o stalking, por si só, justifica o aumento de medo, tensão, nervosismo, raiva, agressividade, confusão, desconfiança, paranóia, cansaço, fraqueza, cefaleias, náuseas, perturbações do sono e do apetite, tristeza, depressão e PTSD”. A vítima pode desenvolver ideação suicida e outras perturbações de ansiedade, e até mesmo perturbações da personalidade ou o agravamento de doenças como asma, hipertensão e psoríase, por influência psicossomática (Pathé et al., 2001, cit. in Coelho \& Gonçalves, 2007).

Para além dessas alterações emocionais e físicas, o assédio persistente/perseguição leva a dificuldades económicas, já que muitas vezes se verifica a redução das horas de trabalho, ou mesmo o abandono laboral, o aumento dos gastos com segurança e com a mudança de residência, a substituição dos bens roubados ou vandalizados, além do afastamento da vítima do convívio social, diante do sentimento de medo, vergonha e humilhação. Hall (1998, cit. in Coelho \& Gonçalves, 2007) aponta casos em que a vítima afastou-se dos familiares, chegando ao ponto de mudar de nome e aparência como forma de escapar da intrusão do stalker. Verifica-se assim que, para além da vítima, seus familiares, principalmente filhos, acabam por sofrer também com o stalking.

Bem como Coelho e Gonçalves (2007) ressaltam, não são todas as vítimas que passam por essas sintomatologias, já que o reflexo dos atos de intrusão são diferenciados em cada vítima, assim como o tipo de assédio persistente/perseguição que sofrem; por outro lado há também diferenças nas próprias características da vítima, no que tange às suas fragilidades e às estratégias de coping empregadas. Nesta senda acrescem McEwan, Mullen \& Purcell (2007, cit. in Matos et al., 2012) que o impacto nas vítimas pode ser aumentado, de acordo com as vulnerablidades já existentes antes da perpetração do assédio persistente/perseguição. Neste caso é possível indicar que, quanto mais intrusivas e mais diversas forem as condutas, assim como quanto maior for a sua duração, maior poderá ser o dano à vítima, na esfera psicológica e social.

4 No Canadá, no Reino Unido e em alguns estados do Estados Unidos, o medo vem como componente indispensável para a caracterização do tipo penal de stalking. Diante disso, Matos e colaboradores (2012) desenvolveram um estudo publicado com título "Vitimação por stalking, preditores do medo", o qual contou com uma amostra de 236 participantes (67,8\% do sexo feminino) entre os 16 e os 94 anos, que foram vítimas de stalking em algum momento da vida. Nessa pesquisa vislumbrou-se que o medo foi apontado como consequência da vitimação por $68,2 \%$ dos participantes. Cabe ressaltar que caso o medo fosse apresentado como critério de definição do stalking, mais de $30 \%$ dos participantes que se autoidentificaram vítimas teriam sido excluídos da amostra; por isso a componente medo causa desconsenso na literatura, quanto a sua necessidade para a configuração do stalking. 
Há ainda a considerar outros aspectos do fenómeno para os quais a literatura científica vem criando classificações, como por exemplo, um perfil para o stalker ${ }^{5}$ e para a vítima ${ }^{6}$, estratégias de coping $^{7}$ empregadas por esta última para findar com o assédio/perseguição, a relação pré-existente ${ }^{8}$ entre perpetrador e alvo, entre outras.

\section{Prevalência no mundo}

É através da percepção do fenómeno - os motivos e as consequências - e da determinação de padrões que possibilitem reconhecer um stalker e seu alvo, que a comunidade científica vem contribuindo para um maior interesse das autoridades. E isso se torna essencial para a fomentação do interesse pela

${ }^{5}$ Sheridan e colaboradores (2003, cit. in Coelho \& Gonçalves, 2007) delinearam o perfil dos stalkers como indivíduos do sexo masculino, com idades entre os 35 e os 40 anos (idades superiores à dos criminosos) e solteiros ou divorciados, o que pode significar o fracasso nas suas relações afetivas, o que se coaduna com a frequência de os stalkers serem ex-parceiros de suas vítimas.

${ }^{6}$ No que tange a vítima, na maior parte dos casos são do sexo feminino, com idades compreendidas entre os 18 e os 30 anos (Tjaden \& Thonnes, 1998, cit. in Costa, 2011), solteiras ou vivendo sozinhas, estudantes ou com um emprego em que existe contacto com o público (Sheridan, 2003, cit. in Coelho \& Gonçalves, 2007). Mustaine e Tewksbury (1999, cit. in Coelho \& Gonçalves, 2007) apontaram que as funções públicas, de profissionais da saúde (Lima, 2010), estudantes e políticos são cargosque demandam maior contacto social, com uma rotina fixa, e por isso são mais vulneráveis ao assédio persistente/perseguição do stalker. Brewster (2003, cit. in Coelho \& Gonçalves, 2007) aponta que as mulheres com história prévia de maus-tratos físicos e com filhos, que estão buscando o fim do relacionamento abusivo, também são vítimas frequentes do assédio/perseguição. Tjaden e Thoennes (1998, cit. in Coelho \& Gonçalves, 2007) ressaltam que, para além das mulheres com as características acima descritas, os homens homossexuais são também alvos comuns de stalking, devido ao preconceito com a sua orientação sexual.

7 Citados por Ferreira e Matos (2013), Spitzberg e Cupach (2001, 2007; Spitzberg, 2002) criaram uma tipologia de coping que organiza as estratégias tipicamente adotadas pelas vítimas de stalking (em geral) em cinco categorias principais: Moving With corresponde à negociação com o stalker; Moving Against consiste em tentativas da vítima em confrontar o stalker (e.g., ameaçar, agredir), as quais são desaconselhadas; na estratégia Moving Away, as vítimas procuram evitar o stalker e qualquer possibilidade de contacto ou interação com aquele; Moving Inward consiste na opção da vítima em negar, minimizar ou redefinir a situação, por exemplo, através do recurso à medicação ou consumo de substâncias; por fim, o Moving outward centra-se na procura de apoio junto de terceiros, quer formal quer informal, o qual é globalmente tido como eficaz.

${ }^{8}$ Para além da identificação de um perfil de risco das vítimas ou do próprio stalker, a literatura estrangeira também buscou criar classificações para o stalking, que refletem a situação relacional, isto é, conforme a existência ou não de uma relação entre vítima e stalker anteriormente ao assédio/perseguição. Quando o stalking ocorre entre estranhos, comumente o alvo é uma figura pública; Mohandie (2006, cit. in Carvalho, 2010) apontou que nesses casos a maior parte dos stalkers é do sexo feminino, e as vítimas do sexo masculino, transparecendo uma relação entre artista e fã. Dificilmente nesses casos há agressão física. Relativamente ao stalking entre estranhos em que ambas as partes são pessoas comuns, Mohandie (2006, cit. in Carvalho, 2010) verificou uma maior possibilidade de um quadro de psicopatologia; neste caso, as motivações são relacionadas com ilusões amorosas, podendo resultar em agressão à vítima, assim como causar danos aos bens patrimoniais do alvo.

O stalking entre conhecidos é o mais comum, em que a vítima e o perpetrador fazem parte de um mesmo círculo de relações sociais e pessoais. Pod haver distintas motivações, desde desavenças por divergências de opinião, por disputa de posto de trabalho, até pela rejeição ou fim de uma relação íntima. Neste caso a escalada de violência pode ser mais recorrente, visto que o stalker tem maior acesso à vítima e ao seu cotidiano; pode haver uma conexão entre o stalking e a violência doméstica, pois a proximidade entre o ofensor e a vítima permite maiores desentendimentos e, consequentemente, agressões de diferentes naturezas - psicológicas e físicas (Carvalho, 2010). 
temática e pela criação de políticas públicas, de entidades de apoio às vítimas, e até mesmo de uma legislação anti-stalking específica.

Excepcionando a Dinamarca, que possui uma legislação que pode ser enquadrada como anti-stalking desde os anos trinta do século passado, os Estados Unidos foram o primeiro país a se preocupar com a tipificação do stalking devido a um incidente com a atriz Rebecca Schaeffer, e algumas outras mulheres, que teve grande repercussão na mídia em 1990. E com a criminalização muitas foram as investigações em torno do fenómeno stalking, de modo que os estudos desenvolvidos nesse país servem de referência para pesquisas em outros países.

Na Europa, a Comissão Europeia financiou o Modena Group on Stalking (2007), formado por representantes de diversos países, que fez análises comparativas entre os resultados de estudos ${ }^{9}$ sobre stalking nos países da União Europeia. Quando do estudo, a União Europeia integrava 25 países, dos quais apenas oito possuíam legislação específica anti-stalking - Áustria (2006), Bélgica (1998), Dinamarca (1933), Irlanda (1997), Holanda (2000), Alemanha (2007), Malta (1997) e Reino Unido (1997). Hoje são 28 países que integram a União Europeia, e mais seis países tipificaram o fenómeno nos últimos anos - Itália (2009), Luxemburgo (2009), República Checa (2010), Polônia (2011), Suécia (2011) e Portugal (2015).

Os estudos em torno do stalking são recentes em Portugal: o primeiro artigo científico português é do ano de 2007 e nele se apresentou o estado da arte deste fenómeno na esfera internacional. Nos últimos anos a temática vem sendo desenvolvida a partir de alguns estudos, principalmente na área da Psicologia, onde muitos são os trabalhos voltados para a vitimação. Uma referência nacional nessas pesquisas é o Grupo de Investigação de Stalking em Portugal (GISP) da Universidade do Minho, que desde 2009/2010 busca inserir

\footnotetext{
9 Um desses estudos foi o Relatório Criminal Anual do Reino Unido do ano de 1998 (cit. in Carvalho, 2010) em que se constatou que $4 \%$ das mulheres e $1,7 \%$ dos homens haviam sido vítimas de perseguições persistentes e não desejadas no ano anterior. Por outro lado, no caso alemão, a partir das investigações de um grupo de estudos (cit. in Carvalho, 2010) verificou-se que o stalking alcançava uma percentagem de $11,6 \%$ das vitimações existentes. No caso italiano, o National Statistics Institute (ISTAT) (cit. in Carvalho, 2010) revelou uma taxa de 18,8\% em uma amostra feminina, em contexto de violência doméstica no momento de separação/divórcio. Foi estimado que $9 \%$ do total da população sueca experienciaram o fenómeno em algum momento da vida; dessa percentagem, um quarto são homens e três quartos mulheres (Dovelius et al., 2006, cit. in Carvalho, 2010).

Apesar de haver tipificação do stalking na Bélgica, este país não possuía até o momento da pesquisa do Modena Group on Stalking qualquer estudo de prevalência; por isso, foram consideradas as estatísticas de condenações efetivas posteriores à implementação da lei anti-stalking, nas quais se verifica um aumento de 10 para 308 casos, de 1999 para 2003 (Carvalho, 2010). Na mesma senda, diante da inexistência de estudos sobre a prevalência do fenómeno, na Holanda foi reportado o número de casos conhecidos desde o ano 2000; após a tipificação do assédio persistente/perseguição, o tribunal conheceu 1947 ações, das quais 1811 resultaram em condenação por stalking (Malsch, 2007b, cit. in Carvalho, 2010). Na Dinamarca a avaliação do fenômeno também foi feita através do número de processos existentes; segundo Kyvsgaard (2007, cit. in Carvalho, 2010), no ano de 2005, houve 935 casos de violação do artigo 265 do Código Penal dinamarquês, no qual se criminaliza o stalking; e desses casos, 840 se concretizaram em acusação.
} 
o stalking na agenda política, social, científica e criminal. No ano de 2011, o manual para profissionais "Stalking: Boas práticas no apoio à vítima”, inserido no projeto "Stalking em Portugal: Prevalência, impacto e intervenção" (PIHM/ VG/0090/2008), compilou os principais resultados do "Inquérito de Vitimação por Stalking: Relatório de Investigação", uma das primeiras pesquisas com a população portuguesa, que evidenciou a prevalência do fenómeno stalking.

O Relatório de Investigação foi um estudo pioneiro no país. Visou o conhecimento da prevalência da vitimação por stalking em território nacional, para auxiliar no desenvolvimento de estratégias de intervenção no apoio às vítimas (Matos et al., 2011). O Relatório buscou desocultar o fenómeno e caracterizá-lo, assim como verificar o impacto nas vítimas e a forma de apoio a que essas recorrem quando sofrem a campanha de assédio, servindo de fonte para o desenvolvimento de medidas de intervenção.

$\mathrm{Na}$ meta-análise dos resultados de 175 amostras distintas (população clínica/forense, estudantes universitários e amostras da comunidade), desenvolvida por Spitzberg e Cupach (2007, cit. in Matos et al., 2011), identificou-se uma prevalência do fenómeno em $19,5 \%$ da amostra total, de modo que a prevalência oscila entre $8 \%$ e $32 \%$ nas vítimas do sexo feminino, e entre $2 \%$ e $13 \%$ nas vítimas do sexo masculino. Em Portugal os resultados do Relatório apontam para $25 \%$ de mulheres e $13,3 \%$ de homens como vítimas de stalking. As autoras do Relatório apontam que as taxas de Portugal encontram-se nos intervalos internacionais apontados, contudo aproximam-se dos limites superiores; isso pode ocorrer pelo fato de na pesquisa portuguesa o stalking ser apresentado sem a inclusão do critério medo em sua definição. Dressing, Kuehner e Gass (Matos et al., 2011) afirmam que, diante da ausência de uma definição singular, ocorrem oscilações nas taxas de prevalência consoante os critérios de vitimação, o que acaba por ser um complicador na visualização do fenómeno.

Outros aspectos a ter em conta no stalking em território nacional e noutros países são, por um lado, o fato de a taxa de vítimas do sexo feminino $(67,8 \%)$ ser superior à das vítimas do sexo masculino, e, por outro, o fato de o stalker ser do sexo masculino (68\%) na maior parte dos casos. A literatura internacional revela que o "ser mulher", ser solteira, separada ou divorciada, assim como ter entre 16 e 29 anos, são fatores de risco para ocorrer stalking. Estes dados se assemelham ao estabelecido na literatura nacional, em que o sexo, o estado civil e a idade são fatores de risco para a vitimação (Matos et al., 2011).

No mesmo sentido, coadunando com os estudos internacionais o tipo de relação existente entre a vítima e o stalker, o Relatório apontou para mais de $70 \%$ de os stalkers serem conhecidos da vítima; dentre eles 31,6\% eram atuais ou ex-parceiros, e 25\% desconhecidos (Matos et al., 2011).

Outros exemplos de investigações desenvolvidas no país, nomeadamente pelo GISP, são a tese de doutoramento de Helena Maria Fernandes Grangeia (2012), que tratou sobre a prevalência e caracterizou e verificou estratégias 
de coping das vítimas em jovens e adultos, bem como os trabalhos de Célia Isabel Lima Ferreira (2012), que tratou desses mesmos aspectos mas voltada para as vítimas de violência doméstica, e de Débora Alexandra Morais Teixeira da Mota (2010), que trabalhou com a comunidade homossexual. Já Susana Manuela Fernandes Costa (2011) buscou recolher informações quanto à experiência de vitimação - comportamentos sofridos, duração e frequência por parte dos profissionais da saúde. Outra linha de pesquisa desenvolvida pelo GIPS referiu-se aos estudos em torno das percepções de profissionais quanto ao fenómeno. Ana Lúcia Carvalho Lima (2010) trabalhou com os profissionais de saúde, Teresa Raquel da Silva Gomes (2010) e Leandra Maria Morais Rodrigues (2010) com os profissionais de apoio à vítima, Maria Manuel Carvalho Teibão de Abreu (2009) vislumbrou as percepções dos profissionais da GNR, e E. P. D. Braga e F. S. Pereira (2010) fizeram estudos com amostra de estudantes universitários. Para além dessas duas perspectivas, Hugo André da Conceição Borges (2010) fez um comparativo da percepção entre vítimas e não vítimas de violência doméstica no que tange o fenómeno, e Célia Sofia de Sousa Carvalho (2011) desenvolveu o primeiro estudo sobre o ciberstalking.

Assim, verifica-se que as pesquisas nacionais foram relevantes para o reconhecimento do fenómeno no território nacional, e consequentemente para a criação de um tipo penal específico para essas situações, como veremos na próxima seção. Ainda, os resultados das pesquisas serviram como base de fundamentação na decisão de alguns magistrados portugueses, em data anterior à publicação de uma lei anti-stalking, como será possível ver nos Acórdãos selecionados.

\section{0 caso português}

Assim como ocorreu na Holanda e em outros países, a introdução de uma lei anti-stalking trouxe e traz controvérsias, não só pela ausência de uma definição uniforme, como pela presença no arcabouço penal de diversos tipos penais aparentemente cabíveis as situações que caracterizam o "crime" de stalking.

Apesar da nova tipificação de "Perseguição", diversos são os tipos penais que estavam sendo empregados para suprir a não existência de um tipo penal de stalking, tais como os artigos 131..$^{\circ}$ (homicídio), 143. . (ofensa à integridade simples), $144 .^{\circ}$ (ofensa à integridade grave), $152 .^{\circ}$ (violência doméstica), $153 .{ }^{\circ}$ (ameaça), 154..$^{\circ}$ (coação), 163. (coação sexual), 164..$^{\circ}$ (violação), $16 .^{\circ}$ (abuso sexual de pessoa incapaz de resistência), $170 .^{\circ}$ (importunação sexual), $180 .^{\circ}$ (difamação), $181 .^{\circ}$ (injúria), $1900^{\circ}$ (violação de domicílio ou perturbação da vida privada), $192 .^{\circ}$ (devassa da vida privada), $193 . .^{\circ}$ (devassa por meio de informática cyberstalking) e 199. (gravações e fotografias ilícitas). Assim, a possibilidade de processamento e consequente condenação dos atos de um stalker, mesmo quando estávamos perante a ausência de uma lei específica anti-stalking, se evidencia com a análise dos Acórdãos da Relação a seguir apresentados. 


\subsection{Acórdãos}

A pesquisa restringiu-se aos Acórdãos dos Tribunais da Relação portugueses que referiram o termo stalking até maio de 2015, última decisão anterior ao aditamento do Código Penal português. Foi utilizado o site "Bases JurídicoDocumentais", do Instituto de Gestão Financeira e Equipamentos da Justiça I.P (IGFEJ), disponível no link http://www.dgsi.pt/, por meio da pesquisa livre, com o emprego da palavra stalking para fazer a busca.

Apesar da ausência de legislação específica para o fenómeno até agosto de 2015, os Tribunais portugueses já vinham assimilando o termo stalking associando-o a outras condutas já tipificadas pelo Código Penal - violência doméstica, ameaça, coação, perturbação da paz e sossego, injúria, etc.

No ano de 2010, o douto Tribunal da Relação de Évora, referenciou pela primeira vez em Portugal o termo stalking, como condutas que consistem na prática do crime de perturbação da paz e sossego, descritos no artigo $190 .^{\circ}$ do Código Penal (Processo n. ${ }^{\circ}$ 741/06.9TAABF.E1), referenciando as embrionárias pesquisas nacionais sobre o fenómeno. E de lá para cá houve mais sete julgados (765/08.1PRPRT.P2; 956/10.5PJPRT.P1; 113/10.0TAVVC.E1; 956/10.5PJPRT. P1; 60/13.4PCLRA.C1; 91/14.7PCMTS.PI e o 43/12.1GCOVR-A.P1) que trazem em seu bojo alguma discussão quanto a esse fenómeno, sendo três do corrente ano. A seguir, breve comentários sobre cada processo.

\subsubsection{Processo n. ${ }^{0}$ 741/06.9TAABF.E1}

No ano de 2010, o douto Tribunal da Relação de Évora, referenciou pela primeira vez em Portugal o termo stalking, no Recurso Criminal do Processo n. ${ }^{\circ}$ 741/06.9TAABF.E1. Diante dos comportamentos perpetrados pelo Recorrente contra a Assistente, o Relator comentou "que a actuação do recorrente abrange condutas conhecidas por Stalking que vêm preocupando os psicólogos portugueses e que algumas legislações europeias punem autonomamente", mencionando o estudo da Dr. ${ }^{a}$ Carla Alexandra dos Santos Paiva, psicóloga clínica, investigadora da Universidade do $\mathrm{Minho}^{10}$. Apresentando ao longo do Acórdão alguns dados estatísticos com o fim de demonstrar quais as condutas mais comuns de um stalker, tais como: perseguir, telefonar, enviar cartas, observar e vigiar, rondar as proximidades do local de trabalho ou residência da pessoa, etc., acrescentou que as condutas de stalking poderiam ser desde ações simples até atos altamente intimidatórios. Foi referida a proximidade entre o stalking e o crime de violência doméstica ${ }^{11}$, assim como ressaltada a importância dos

\footnotetext{
10 O Relator referiu que: "o Stalking, definido como um síndrome comportamental decorrente de uma patologia das relações interpessoais e da comunicação, inclui uma série de acções repetidas ao longo do tempo, partilha características de vigilância e controlo, procura de contactos e comunicação e é percebido pela vítima como capaz de despertar, e efectivamente despertando (arousing), ansiedade e medo." 11 Este fenómeno e a violência doméstica como forma de vitimação relacional andam muitas vezes de mãos dadas. São casos de relações que terminaram e em que uma das partes não aceita ou desenvolve uma fixação obsessiva por alguém.
} 
estudos nacionais, que estavam então a iniciar-se, para asseverar a existência da conduta típica de stalking, e das particularidades encontradas em território nacional.

O Relator trouxe à tona uma grande discussão vigente hoje nos estudos sobre stalking, principalmente na literatura estrangeira, no que se refere à exigência ou não da componente "medo" para se configurar o crime de stalking. Em alguns países - Estados Unidos, Malta, Holanda e Austrália - é exigida esta componente, diferentemente do que sucede na Alemanha e na Áustria, onde não é um requisito para o preenchimento do tipo penal.

Afirmou o ilustre desembargador que, apesar de ter havido a revisão do Código Penal em 2007, o legislador português não inseriu o tipo penal de stalking, e assim não foram criminalizadas todas as condutas possíveis do fenómeno, deixando com isso de "fora condutas que constituem verdadeiros atentados aos direitos dos cidadãos".

\subsubsection{Processo n.. 765/08.1PRPRT.P2}

Em novembro de 2012 no Tribunal da Relação do Porto, no Processo n. ${ }^{\circ}$ 765/08.1PRPRT.P2, o Relator Pedro Vaz Pato referiu as condutas de perturbação da paz e sossego como características de stalking ${ }^{12}$ e ressalvou que o n. ${ }^{\circ} 2$ do artigo $190 .^{\circ}$ do Código Penal foi acrescentado pela Lei n. ${ }^{\circ}$ 59/2007, inserindo assim a perturbação da vida privada por telefonema como um tipo penal, com o fim de abranger as condutas conhecidas por stalking; com isso o comportamento do recorrente poderia ser enquadrado na situação de stalking ${ }^{13}$.

O Recorrente interpôs recurso sob a alegação de que a palavra "telefonar" no artigo $190 .^{\circ}$, n. $^{\circ} 2$ do Código Penal não abrangia as mensagens escritas (sms) e por isso não havia o preenchimento do tipo legal.

Todavia o Relator compreendeu que "as referidas mensagens por telemóvel emitem sinal auditivo, em tudo igual ao telefonema, e compelem a pessoa a manusear o aparelho e a desligar o ruído que emite, mesmo que decida não tomar conhecimento imediato do teor da comunicação". Assim, o "telefonar" significa "comunicar pelo telefone", ou fazer "uso do telefone". Verificando que a Assistente teve "a sua paz e sossego perturbada pelo envio, por parte do Arguido, de mensagens escritas por telemóvel”, o Tribunal da Relação negou provimento ao recurso e manteve a sentença $a$ quo.

\footnotetext{
12 Sumário do Acórdão: "Integra a prática do crime p. e p. pelo artigo $190 .^{\circ}$, n. ${ }^{\circ} 1$ e 2 , do Código Penal e envio de mensagens escritas (sms) através de telemóvel com a intenção de perturbar a vida privada, a paz e o sossego de outra pessoa.”

13 O Relator afirmou que stalking é uma "forma de violência já criminalizada autonomamente em vários países, em que o sujeito ativo invade repetidamente a esfera de privacidade da vítima, empregando táticas de perseguição e diversos meios, tais como ligações telefónicas, envio de mensagens, espera nos locais de maior frequência, dos quais podem resultar danos à integridade psicológica e emocional da vítima e restrições à sua liberdade de locomoção, face à angústia e temor que tais comportamentos provocam" [grifo no original].
} 


\subsubsection{Processo n. ${ }^{-113 / 10.0 T A V V C . E 1 ~}$}

Em janeiro de 2013, o Relator do Tribunal da Relação de Évora, João Gomes de Sousa, no Recurso Penal do Processo n. ${ }^{\circ}$ 113/10.0TAVVC.E1, citou a presença de stalking em uma situação de violência doméstica, discutindo a Punição pelo crime de violência doméstica, ou então, pela totalidade dos seguintes tipos penais cabíveis ${ }^{14}$. O Relator enquadrou a conduta na tipificação de violência doméstica, em face de ter trazido maiores consequências à vítima, visto a existência de laços afetivos entre as partes, e, diante dos comportamentos do Recorrente, referi à presença de stalking ${ }^{15}$ na violência doméstica. O Relator considerou o stalking como "perseguição persistente; alguém que importuna de forma insistente e obsessiva uma outra pessoa", com base no artigo "Stalking: uma nova dimensão de violência" (2007) de Rui Abrunhosa Gonçalves e Cláudia Coelho.

Diante da análise de todo o processo, entendeu-se pela negação do provimento, por se considerar demonstrado que houve "agressões, humilhações, ameaças, injúrias, coacções, sequestro e um conjunto de actos e afirmações claramente violadores da intimidade da ofendida, através do uso de fotografias ilícitas e de devassa da vida privada. Com reflexos na sua saúde psíquica e emocional, como os factos revelam". Reconheceu-se que os atos analisados isoladamente não possuíam gravidade, mas, verificados em conjunto, e diante da reiteração, implicavam "reflexos na dignidade da ofendida".

\subsubsection{Processo n.ํำ 956/10.5PJPRT.P1}

No processo n..$^{\circ}$ 956/10.5PJPRT.P1 do Tribunal da Relação do Porto de outubro de 2014, o Relator Moreira Ramos inseriu no sumário a correlação entre o envio de sms e o stalking ${ }^{16}$. Ao referir-se ao stalking, o Relator reconheceu a inexistência de sua tipificação no país; entretanto, considerou que o arcabouço penal português abarcava essas situações com o crime de violência doméstica, por serem semelhantes, enquadrando o caso no artigo $152 .^{\circ}$ do Código Penal ${ }^{17}$.

\footnotetext{
14 “ofensas corporais simples (artigo 143..$^{\circ}$,.$^{\circ} 1$ do Código Penal), as injúrias (artigo 181..$^{\circ}$ ), a difamação (artigo $180 .^{\circ},{ }^{\circ} .^{\circ}$ ), a coacção (artigo $154 .^{\circ}$ ), o sequestro simples (artigo $158 . .^{\circ}$, n. ${ }^{\circ} 1$ ), a devassa da vida privada (artigo 192..$^{\circ}$,.$^{\circ} 1$, al. b), as gravações e fotografias ilícitas (artigo 199., n. ${ }^{\circ} 2$, al. b).”

${ }_{15}$ O Relator afirmou que, "para estes casos de pluralidade factual integradora de vários tipos penais e no âmbito de uma relação conjugal ou equiparada mas sempre inserido numa relação com carácter de conjugalidade ou de vivência - ou anteriormente inserido e que dêem origem a uma situação de stalking - e de que dão nota as várias alíneas do n. ${ }^{\circ} 1$ do preceito, previu o legislador um tipo autónomo que se entende tutela específica da vida em relação, que pode fazer nascer uma relação de dependência e, consequentemente, de vítima de violências várias, emocional e psicológica, intimidante (coacção e ameaças), física, de isolamento social, de abuso sexual".

16 "II - No âmbito do crime de violência doméstica, cabem as condutas e comportamentos que causam inclusive através do envio de sms, maus tratos psíquicos configurados como stalking."

17 O Relator defendeu que o "stalking, forma de violência já criminalizada autonomamente em vários países, e que no nosso ordenamento jurídico encontra previsão, com mais acuidade, no crime de violência doméstica, em que o sujeito activo invade repetidamente a esfera de privacidade da vítima, empregando tácticas de perseguição e diversos meios, tais como ligações telefónicas, envio de mensagens, espera nos locais de maior frequência, dos quais podem resultar danos à integridade psicológica e
} 


\subsubsection{Processo n. ${ }^{\circ}$ 60/13.4PCLRA.C1}

Mais recentemente, em janeiro de 2015, no Tribunal da Relação de Coimbra, no Recurso Criminal do Processo n. ${ }^{\circ}$ 60/13.4PCLRA.C1, em que o Recorrente havia sido condenado pela prática do crime de violação de domicílio ou perturbação da vida privada, preconizado pelo artigo $1900^{\circ}$, n. $^{\circ} 2$ do Código Penal, afirma-se que "As mensagens denominadas SMS não integram o conceito de telefonema do artigo $190 .^{\circ}$ n. 2 do Código Penal, uma vez que o legislador podia tê-las integrado e optou por não o fazer". Inferindo que o fato de um dos progenitores "ligar constantemente ao outro" (duas mensagens e alguns telefonemas durante o período de dois meses), para obter informações do filho, mesmo que sendo exagerados, não poderia configurar a insistência de contacto no tipo penal de perturbação. Afirma-se ainda que o caso se desenvolveu a partir de "uma questão de relacionamento e de interpretação acerca da regulação de responsabilidades parentais em vigor, e não entra, de forma alguma, numa devassa, stalking ou qualquer outro acto de perseguição ou de mera perturbação da vida da assistente".

A Relatora não conheceu as questões suscitadas no recurso por compreender que a sentença recorrida era nula, em conformidade com o artigo $379 .^{\circ}, \mathrm{n} .^{\circ}$ 1, al. "b"18 do Código de Processo Penal.

\subsubsection{Processo n. $91 / 14.7 P C M T S . P I$}

Em março de 2015, o Recurso Penal do Processo n. ${ }^{\circ}$ 91/14.7PCMTS.PI foi interposto pelo Arguido diante da sua condenação por um ano e quatro meses de prisão efectiva, pelo crime de violência doméstica, argumentando não ter cabimento o enquadramento penal de violência doméstica no caso, pois as brigas de namoro, "não raras vezes, abrangem violência - sobretudo psicológica".

Entretanto não foi esse o entendimento do Tribunal, o qual compreendeu que a "conduta do arguido provocou perigo para a saúde psíquica e emocional da assistente e, também pelo que representa de vontade de subjugação, atingiu a sua dignidade de pessoa. Assim, a douta sentença recorrida não é, quanto à qualificação jurídica dos factos provados, merecedora de reparo". E diante das condutas do recorrente, o Relator referenciou a presença de stalking ${ }^{19}$ no caso concreto, citando o artigo de Rui Abrunhosa Gonçalves e Cláudia Coelho, que já havia sido citado em decisão anterior (Processo n. ${ }^{\circ}$ 113/10.0TAVVC.E1 do Tribunal da Relação de Évora).

emocional da vítima e restrições à sua liberdade de locomoção, em face da angústia e temor que tais comportamentos provocam".

18 Artigo $379 .^{\circ}$ Nulidade da sentença // 1 - É nula a sentença: [...] b) Que condenar por factos diversos dos descritos na acusação ou na pronúncia, se a houver, fora dos casos e das condições previstos nos artigos $358 .^{\circ}$ e $359 .^{\circ}$.

19 O Relator inferiu o stalking como "uma perseguição prolongada no tempo, insistente e obsessiva, causadora de angústia e temor, com frequência motivada pela recusa em aceitar o fim de um relacionamento. Este tipo de comportamento, que pode assumir maior ou menor intensidade, pode enquadrar-se no crime de violência doméstica”. 


\subsubsection{Processo n.. 43/12.1GCOVR-A.P1}

O sétimo Acórdão, datado de maio de 2015 do Tribunal da Relação do Porto, refere-se a um pedido no qual o Recorrente requeria que não houvesse a transcrição no registo criminal da condenação por ofensa à integridade física qualificada, com pena de dois anos e seis meses de prisão, a qual foi suspensa na sua execução por igual período, assim como não houvesse comunicação à sua entidade empregadora sobre a sentença. Nesse Processo a Relatora Lígia Figueiredo referiu que o Arguido, ora Recorrente, cometera stalking por ter causado ofensa à integridade física por um período de mais de dois anos, não havendo mais nenhuma informação relevante para a discussão do tema.

\subsection{Discussão - Acórdãos}

A partir dos sete Acórdãos que serviram de ilustração para compreendermos o tratamento do stalking antes de sua tipificação no território português, depreendemos que o termo stalking já é conhecido de nossos magistrados desde o início da disseminação das investigações científicas nacionais de prevalência sobre o respectivo tema em 2010.

Os Relatores, em sua maioria, demonstraram que a legislação estava sendo suficiente para repreender todas as situações de stalking. Mas isso pode ser decorrente da não compreensão do stalking como um tipo penal específico/ autônomo. É cristalino que os Relatores tratam o stalking como um termo a ser empregado diante de uma conjugação de condutas, algumas das quais já criminalizadas (agressão física, perturbação, violência doméstica, etc.), em que há uma recorrência dos comportamentos com o fim de estar próximo da vítima e de manter uma relação com esta.

Vislumbra-se ainda a associação entre o stalking e a relação amorosa, em que o primeiro decorre da tentativa de criar, manter ou reatar um relacionamento. Com isso o enquadramento acaba recaindo frequentemente no tipo penal de violência doméstica ${ }^{20}$, como defendeu o Relator Moreira Ramos no Processo n. ${ }^{\circ}$ 956/10.5PJPRT.P1, ao inferir que "no nosso ordenamento jurídico [o stalking] encontra previsão, com mais acuidade, no crime de violência doméstica". Esta afirmação contribui para a sanção do comportamento, contudo leva à negligência do fenómeno de stalking.

Como inferido no "Inquérito de Vitimação por Stalking" desenvolvido pelo GISP, em Portugal, grande parte dos casos de stalking está relacionada com o término de relações afetivas, e por isso o tipo penal de violência doméstica acaba por ser frequentemente aplicado, como o confirma o consenso dos

20 Sobre a alteração do Código Penal em 2007, o Relator Moreira Ramos argumentou que “o legislador de 2007 alargou o âmbito de aplicação do crime de violência doméstica aos maus tratos sobre ex-cônjuges ou ex-companheiros, pela necessidade político-criminal de reagir aos comportamentos retaliatórios e fortemente perturbadores da paz do ex-parceiro perpetrados por aquele que não se conforma com o fim da relação ou não o suporta ver assumir um novo projecto de vida autónomo (fenómeno esse apelidado de stalking pela criminologia)". 
Relatores dos Acórdãos aqui apresentados, que compreendem o stalking como um fenómeno inserido dentro de outros tipos penais, e não como um tipo específico. Em contrapartida a esse entendimento majoritário, o Relator do primeiro Acórdão (Processo n. . 741/06.9TAABF.E1), o desembargador Fernando Ribeiro Cardoso, defendeu a deficiência na alteração do Código Penal feita em 2007, por não ter ampliado melhor a proteção contra esse tipo de "crime", sendo assim o único a estabelecer o stalking como um tipo penal em si mesmo. Podemos considerar que a sua percepção quanto ao fenómeno foi divergente de seus colegas, por aparentemente ter mais conhecimento sobre o tema. Isso porque, em sua fundamentação, caracterizou o possível tipo penal, citando resultados das investigações no campo da prevalência no nos ultimos anos, isto é, quando essas investigações ainda eram embrionárias.

Atenta-se ao número reduzido e quase irrisório de Acórdãos sobre o fenómeno, dada a ausência de uma legislação específica até muito recentemente. Assim, os poucos Acórdãos que existem tratam o stalking mais como um conjunto de ações já tipificadas, repetidas ao longo do tempo, do que um crime per si. Para além desse reconhecimento "secundário" do stalking, verifica-se que em todos os Acórdãos os Arguidos e suas vítimas mantiveram uma relação amorosa, não havendo nenhuma referência a outras possibilidades de stalking, como por exemplo, a tentativa de criar uma relação, seja por um stalker próximo (amigo, vizinho, colega de trabalho), seja por um estranho. Tal não condiz com os resultados das pesquisas de prevalência nacional, o que nos faz concluir que através dos Acórdãos não conseguimos clarificar de forma mais aprofundada a atuação do judiciário no que tange o "crime" de stalking, servindo aqueles mais de ilustração para demonstrar que o fenómeno já era conhecido antes da sua tipificação.

Outro ponto que leva a esse número reduzido de Acórdãos é que diversos delitos que compõem o stalking possuem uma moldura penal pequena. Assim, após o inquérito policial, já com o juiz de instrução, é possível a instauração da suspensão provisória do processo ${ }^{21}$, preconizada pelo artigo $281 .^{\circ}$ do Código de Processo Penal. Com isso, a única forma de aceder à atuação do judiciário

21 Cabe aqui fazer uma breve explicação sobre a suspensão provisória do processo: ela é estabelecida nos casos em que o crime é punível com pena de prisão não superior a cinco anos ou com sanção distinta de prisão, em que o Ministério Público (de forma oficiosa ou a requerimento do arguido ou do assistente) determina a suspensão do processo, desde que haja concordância do juiz de instrução. Com essa suspensão há a imposição de medidas de injunções e regras de condutas a serem cumpridas pelo arguido (Carvalho, 2013).

A sua admissão ocorre somente com o preenchimento de todos os pressupostos descritos nas alíneas do artigo $281 .^{\circ}$, n. $^{\circ} 1$ - concordância do arguido e do assistente; ausência de antecedentes criminais do arguido; não haver lugar a medida de segurança de internamento; carácter diminuto da culpa; e que seja possível prever o cumprimento das injunções e regras de condutas impostas.

As medidas de injunção ou as regras de conduta estão preconizadas nas alíneas do n. ${ }^{\circ} 2$ do mesmo artigo, podendo ser oponíveis separadamente ou cumulativamente. São elas: a) indemnizar o lesado; b) dar ao lesado satisfação moral adequada; c) entregar ao Estado ou a instituições privadas de solidariedade social certa quantia; d) não exercer determinadas profissões; e) não frequentar certos meios ou lugares; f) não residir em certos lugares ou regiões; g) não acompanhar, alojar ou receber certas 
nos possíveis casos de stalking em data anterior a sua tipificação seria a partir da análise de inquéritos e processos, visto que aparentemente poucos são os casos que passam para a $2 .^{a}$ instância. Contudo, tal tarefa seria inconcebível diante da impossibilidade de fazer uma pesquisa por meio de palavras-chave como stalking, por não haver uma base de dados com todos os inquéritos e processos de 1. instância; seria por isso necessário um trabalho de leitura de cada inquérito e processo.

Assim os Acórdãos evidenciam apenas uma das facetas da realidade alcançada pelas pesquisas nacionais de prevalência. Com isso podemos concluir que o arcabouço penal português para os Relatores vinha aparentemente sendo suficiente para abarcar as situações de stalking, ao menos quando perpetrador e vítima tivessem tido um relacionamento afetivo em momento anterior. No entanto, mesmo com a existência de outros tipos penais no ordenamento jurídico aplicáveis aos casos, verifica-se que muitos países criminalizaram o stalking.

\section{Considerações finais}

Ribeiro (2012) salvaguarda que o stalking não é um fenómeno singular, mas o resultado da combinação de condutas criminais, que em alguns contextos não são identificadas como crimes, o que obsta à sua identificação e intervenção. Até o primeiro semestre de 2015, quando o stalking ainda não estava reconhecido como uma ofensa em si mesmo, era considerado apenas quando o comportamento perpetrado pelo stalker violasse uma norma já instituída. Pode-se verificar tal situação nos Acórdãos, nos quais ficou evidente o conhecimento

pessoas; h) não ter em seu poder determinados objetos capazes de facilitar a prática de outro crime; i) qualquer outro comportamento especialmente exigido pelo caso.

A duração da suspensão provisória do processo pode chegar aos dois anos, com exceção dos crimes enquadrados como de violência doméstica e contra a liberdade e autodeterminação sexual do menor, que podem ter a suspensão vigente por até cinco anos. Quanto à prescrição do crime, essa fica suspensa, voltando a correr no dia em que cessar a causa de suspensão, conforme o artigo $120 .^{\circ}$ do Código Penal. Atente-se que, ao fim do cumprimento das medidas de injunção e das regras de conduta, o Ministério Público arquiva o processo, e este não mais pode ser reaberto, consoante disposição do artigo $282 .^{\circ}$, n. $^{\circ} 3$ do Código de Processo Penal. No caso de não cumprimento das injunções e regras de comportamento ou de cometimento de crime de mesma natureza, pelo qual o arguido venha a ser condenado, no período de vigência da suspensão, o processo prossegue.

A Diretiva n. ${ }^{\circ} 1 / 2014$, no . $^{\circ} 1$, do Capítulo X, preconiza que, quando for viável a aplicação do instituto de suspensão provisória do processo ao caso de violência doméstica, o Ministério Público deve informar pessoalmente a vítima sobre a possibilidade de aplicar o instituto, e, diante do requerimento da vítima para a aplicação da suspensão, deve o Ministério Público adequar as injunções e regras de conduta ao caso. Marques Carvalho (2013) já havia defendido tal necessidade, entendendo que as injunções e regras de conduta deveriam refletir a preocupação com a proteção da vítima, permitindo a fiscalização por meios técnicos de controlo a distância.

Ainda no mesmo diploma legal, no n. ${ }^{\circ} 6$ do Capítulo X, afirma-se que, diante da existência de outros processos no âmbito do direito da família e das crianças que se relacionem com o caso em apreço para a instituição da suspensão provisória do processo, tem o Ministério Público de obter informações sobre os procedimentos judiciais que correram termos, para poder formular as injunções e regras de conduta, de modo a harmonizá-las. 
pelos Magistrados da existência de stalking a nível nacional, contudo com uma assimilação perfunctória. Isso porque aquelas condutas foram consideradas como um conjunto de comportamentos já tipificados (perturbação da paz e sossego), ou como parte de outros tipos penais (violência doméstica), e não como um crime per si. como foi acentuado ao longo desse estudo, realmente o stalking relaciona-se, ou mesmo, insere-se em outros tipos penais, e talvez por isso tenha sido negligenciado.

Assim, a atenção aos resultados das investigações de prevalência é pertinente quando da criação de uma legislação, por permitirem uma delimitação aproximada do fenómeno, quanto a uma determinada população. Em Portugal as pesquisas apontaram para uma alta prevalência de stalking na população, inferindo que na maior parte dos casos ocorre entre pessoas que já tiveram ou ainda mantêm uma relação afetiva. Entretanto, também demonstram que nem sempre há uma relação entre perpetrador e alvo, podendo até serem desconhecidos; nesses casos a conexão com o crime de violência doméstica torna-se débil.

Perante toda essa explanação, verifica-se que, apesar de este ser um tema recente no campo das investigações nacionais, já foi absorvido, o que evidencia uma influência direta dos resultados das investigações científicas na produção de políticas públicas e na própria produção legislativa; a importância desses estudos demonstra-se ainda numa melhor compreensão da sociedade e, nesse caso, dos litígios existentes.

\section{Referências}

ABREU, M. M. C. T. (2009), Stalking: Percepção dos Profissionais da Guarda Nacional Republicana. Dissertação de Mestrado em Psicologia da Justiça - Universidade do Minho, Braga.

BORGES, H. A. C. P. (2010), Stalking: Percepções de "razoabilidade” junto de vítimas e não vitimas no contexto das relações de intimidade. Dissertação de Mestrado Integrado em Psicologia, Área de Especialização em Psicologia da Justiça - Universidade do Minho, Braga.

CARVALHO, C. S. S. (2011), “Ciberstalking”: prevalência na população universitária da Universidade do Minho. Mestrado Integrado em Psicologia, Área de especialização em Psicologia da Justiça. Disponível em: http://repositorium.sdum.uminho.pt/bitstream/1822/18638/1/ C\%C3\%A9lia\%20Sofia\%20de\%20Sousa\%20Carvalho.pdf. Acesso: março de 2015.

CARVALHO, M. P. L. (2010), O combate ao stalking em Portugal: contributos para a definição de um protocolo de intervenção policial. Dissertação de Mestrado em Medicina Legal Instituto de Ciências Biomédicas Abel Salazar da Universidade do Porto, Porto. Disponível em: http://repositorio-aberto.up.pt/bitstream/10216/26593/2/STALKINGVersaoPB.pdf. Acesso: março de 2015.

CARvalHo, P. M. (2013), Manual prático de Processo Penal. (7. ed.). Coimbra: Almedina.

COELHO, C. \& GONÇALVES, R. A. (2007), "Stalking: uma outra dimensão da violência conjugal”. Revista Portuguesa de Ciência Criminal. Coimbra: Coimbra Editora, 269-302.

COSTA, S. M. F. (2011), "Stalking": prevalência junto de profissionais de saúde mental. Dissertação de Mestrado Integrado em Psicologia, Área de Especialização em Psicologia da Justiça - Universidade do Minho, Braga. Disponível em: http://repositorium.sdum.uminho. 
pt/bitstream/1822/18632/1/Susana\%20Manuela\%20Fernandes\%20Costa.pdf. Acesso: março de 2015.

FERREIRA, C. I. L. (2012), Stalking pós-rutura: Das características aos significados das mulheres vítimas. Tese de Doutoramento em Psicologia, Especialidade em Psicologia da Justiça Universidade do Minho, Braga.

FERREIRA, C. \& MATOS, M. (2012). "Violência doméstica e stalking pós-rutura: dinâmicas, coping e impacto psicossocial da vítima”. Psicologia, vol. XXVII(2), Lisboa: Edições Colibri, 81-106. Disponível em: http://www.scielo.gpeari.mctes.pt/scielo.php?pid=S0874-20492013000200004\&script=sci_arttext. Acesso: março de 2015.

GOMES, L. F. (2012), “Criminalização do stalking: perseguição obsessiva pode se tornar novo tipo penal”. Publicado em 4 de junho de 2012. ConJur. Disponível em: http://www.conjur. com.br/2012-jun-04/perseguicao-obsessiva-chamada-stalking-tornar-tipo-penal. Acesso: junho de 2015.

GOMES, T. R. S. (2010), Stalking: O efeito da severidade da conduta e do tipo de relação nas percepções de razoabilidade dos profissionais de apoio a vítimas. Dissertação de Mestrado Integrado em Psicologia, Área de Conhecimento em Psicologia Clínica - Universidade do Minho, Braga.

LIMA, A. L. C. (2010), Razoabilidade das percepções de stalking: O efeito da severidade da conduta e do tipo de relação entre alvo-perpetrador nas perceções dos profissionais da saúde. Dissertação de Mestrado em Psicologia da Justiça - Universidade do Minho, Braga.

LUZ, N. M. L. (2012), Tipificação do crime de stalking no Código Penal português. Introdução ao problema. Análise e proposta de lei criminalizadora. Faculdade de Direito - Universidade Católica Portuguesa, Lisboa. Disponível em: http://repositorio.ucp.pt/bitstream/10400.14/8952/1/TESE.pdf. Acesso: março de 2015.

MATOS, M. (coord.); GRANGEIA, H.; FERREIRA, C. \& AZEVEDO, V. (2011), Inquérito de Vitimação por Stalking: Relatório de Investigação. Grupo de Investigação sobre Stalking em Portugal. Escola de Psicologia, Universidade do Minho, Braga.

MATOS, M.; GRANGEIA, H.; FER REIRA, C. \& AZEVEDO, V. (2011). Stalking: Boas práticas no apoio à vítima, Manual para profissionais. Porto: Comissão para Cidadania e Igualdade de Género. Disponível em: http://www.igualdade.gov.pt/IMAGES/STORIES/DOCUMENTOS/ DOCUMENTACAO/PUBLICACOES/STALKING.PDF. Acesso: março de 2015.

MATOS, M.; GRANGEIA, H.; FERREIRA, C. \& AZEVEDO, V. (2012), "Vitimação por stalking: preditores do medo”. Análise Psicológica, XXX (1-2): 161-176. Disponível em: http://www.scielo.oces.mctes.pt/scielo.php?pid=S0870-82312012000100013\&script=sci_ arttext\&tlng=pt. Acesso: março de 2015.

MOTA, D. A. M. T. (2010), Stalking: prevalência na população homossexual. Dissertação de Mestrado em Psicologia da Justiça - Universidade do Minho, Braga.

MODENA GROUP ON STALKING (2007). Protecting women from the new crime of stalking: a comparison of legislative approaches within the European Union. Daphne Project 05-1/125/ W. Disponível em: http://stalking.medlegmo.unimo.it/RAPPORTO_versione_finale_011007. pdf. Acesso: abril de 2015.

PEREIRA, V. S. \& LAFAYETTE, A. (2008), Código Penal Anotado e Comentado: Legislação conexa e complementar. Lisboa: Sociedade Editora.

PINHAL, D. C. M. (2013), Stalking: um “crime” de assédio persistente? Dissertação de Mestrado em Direito, Área de Ciências Jurídico-Forenses da Faculdade de Direito - Universidade de Coimbra, Coimbra.

ROSA, A. M. (2012). Stalking e a Criminalização do Cotidiano. Rio de Janeiro: R. EMERJ, 15 (60): 72-79. Disponível em: http://www.emerj.tjrj.jus.br/revistaemerj_online/edicoes/ revista60/revista60_72.pdf. Acesso: junho de 2015. 


\section{LEIS, DECRETOS, RESOLUÇÕES E PARECERES}

Associação Portuguesa de Apoio à Vítima (APAV). Parecer da APAV sobre as implicações legislativas da Convenção de Istambul do Conselho da Europa para a Prevenção e o Combate à Violência contra Mulheres e a Violência Doméstica. Parecer de 6 de junho de 2014. Relator, Lisboa, 1-14. Disponível em: http://apav.pt/apav_v3/images/pdf/Parecer_da_APAV_relativo_ as_implicacoeslegislativas_da_Convencao_de_Istambul.pdf. Acesso: agosto de 2015.

Convenção de Istambul. Diário da República, Resolução da AR, 4/2013 de 21 de janeiro de 2013. Disponível em: https://dre.pt/application/dir/pdf1sdip/2013/01/01400/0038500427. pdf. Acesso: maio de 2015.

Diretiva n. ${ }^{\circ} 1 / 2014$ de 24 de janeiro. Diário da República, 2. ${ }^{a}$ série - N. 17 Ministério Público: a Procuradoria-Geral da República. Disponível em: https://re.pt/application/dir/pdf2s dip/2014/01/017000000/0254202548.pdf. Acesso: junho de 2015.

Lei n. ${ }^{\circ}$ 89/2015 de 5 de agosto. Diário da República, $1 .^{a}$ série. Aditamento do Código Penal. Disponível em: https://dre.pt/application/conteudo/69951093. Acesso: agosto de 2015.

Projeto de Lei n. ${ }^{\circ}$ 647/XII. Partido Social Democrata e CDS-Partido Popular. Altera o Código Penal, criminalizando a perseguição e o casamento forçado. Disponível em: http://app.parlamento.pt/webutils/docs/doc.pdf? path=6148523063446f764c3246795a5868774d546f334e $7 \mathrm{a} 67774 \mathrm{c} 336470626 \mathrm{~d} 6 \mathrm{c} 7561574 \mathrm{e} 7059585270646 \mathrm{~d} 467 \mathrm{a} 4 \mathrm{c} 31684 \mathrm{a} 535339305 \mathrm{a} 5868306233$ $4 \mathrm{~d} 76634770734 \mathrm{e} 6 \mathrm{a} 51334 \mathrm{c} 56684$ a 5353356b62324d3d\&fich=pj1647-XII.doc $\&$ Inline $=$ true. Acesso: maio de 2015.

Projeto de Lei n. ${ }^{\circ} 659 / X I I / 4 .^{\text {a }}$ Partido Socialista. Cria o tipo legal de perseguição no código penal. Disponível em: http://app.parlamento.pt/webutils/docs/doc.pdf?path=61485230634 46f764c3246795a5868774d546f334e7a67774c336470626d6c7561574e7059585270646d $467 \mathrm{a} 4 \mathrm{c} 31684 \mathrm{a} 535339305 \mathrm{a} 58683062334 \mathrm{~d} 76634770734 \mathrm{e} 6 \mathrm{a} 55354 \mathrm{c} 56684 \mathrm{a} 5353356 \mathrm{~b} 6232$ 4d3d\&fich=pj1659-XII.doc\&Inline=true. Acesso: março de 2015.

Projeto de Lei n. ${ }^{\circ}$ 663/XII/4 ${ }^{\text {a }}$ Bloco de Esquerda, Grupo Parlamentar. Cria o tipo legal de perseguição no código penal. Disponível em: http://app.parlamento.pt/DARPages/DAR_FS.aspx ?Tipo=DAR+II+s\%C3\%A9rie + A\&tp=A\&Numero=5\&Legislatura=XII\&SessaoLegislativa =4\&Data=2014-09-19\&Paginas=46-48\&PagIni=0\&PagFim $=0 \&$ Observacoes $=\&$ Suplemen to $=. \&$ PagActual=0\&pagFinalDiarioSupl=\&idpag=700638\&idint $=\&$ idact $=\&$ iddeb. Acesso: março de 2015.

Résolution 1962 de 22 de novembro de 2013 du Conseil de L'Europe - Le harcèlement. Assemblée Parlamentaire. Disponível em: http://assembly.coe.int/nw/xml/XRef/X2H-Xref-ViewPDF. asp?FileID=20299\&lang=fr. Acesso: junho de 2015.

\section{JURISPRUDÊNCIAS}

COIMBRA. Tribunal da Relação de Coimbra. Novos factos, alteração substancial dos factos, alteração não substancial dos factos, alteração da qualificação jurídica, violência doméstica, perturbação, vida privada. Processo n. ${ }^{\circ}$ 60/12.4PCLRA.C1. Relatora desembargadora Maria José Nogueira. 21 de janeiro de 2015.

ÉVORA. Tribunal da Relação de Évora. Injúrias, stalking, nulidade, princípio da investigação, impugnação da matéria de facto, indemnização. Processo n. ${ }^{0}$ 741/06.9TA.ABF.E1. Relator desembargador Fernando Ribeiro Cardoso. 18 de março de 2010.

ÉVORA. Tribunal da Relação de Évora. Violência doméstica. Processo n. ${ }^{\circ}$ 113/10.0TAVVC.E1. Relator desembargador João Gomes de Sousa. 08 de janeiro de 2013.

PORTO. Tribunal da Relação do Porto. Crime de violência doméstica, prova documental, SMS (short message service). Processo n. ${ }^{\circ}$ 956/10.5PJPRT.P1. Relator desembargador Moreira Ramos. 08 de outubro de 2012. 
PORTO. Tribunal da Relação do Porto. Crime de perturbação da paz e do sossego, mensagens escritas. Processo n. ${ }^{0}$ 765/08.1PRPRT.P2. Relator desembargador Pedro Vaz Pato. 07 de novembro de 2012.

PORTO. Tribunal da Relação do Porto. Violência doméstica, stalking. Processo n. ${ }^{\circ}$ 91/14.7PCMTS.P1. Relator desembargador Pedro Vaz Pato. 11 de março de 2015.

PORTO. Tribunal da Relação do Porto. Transcrição no Registo Criminal Pena Suspensa. Processo n. ${ }^{\circ}$ 43/12.1GCOVR-A.P1. Relatora desembargadora Lígia Figueiredo. 06 de maio de 2015. 